\title{
Hubungan Aktifitas Fisik, Kepatuhan Mengkonsumsi Obat Anti Diabetik dengan Kadar Gula Darah Pasien Diabetes Mellitus di Fasyankes Primer Klaten
}

\author{
Cahyono Widodo ${ }^{1}$, Didik Tamtomo², Ari Natalia Prabandari ${ }^{2}$ \\ ${ }^{1}$ Prodi Magister Kedokteran Keluarga Program Pascasarjana, Universitas Negeri Sebelas Maret, \\ ${ }^{2}$ Kedokteran Keluarga Program Pascasarjana, Universitas Negeri Sebelas Maret
}

\begin{abstract}
Abstrak
Diabetes mellitus (DM) merupakan sekelompok penyakit metabolik berkarakteristik hiperglikemia karena adanya kelainan sekresi insulin. Selain kematian, DM juga menyebabkan kecacatan pasien. 30\% pasien DM mengalami kebutaan akibat komplikasi retinopati dan 10\% amputasi tungkai kaki, sehingga penatalaksanaan DM sangatlah penting. Keberhasilan pengelolaan DM dapat dicapai melalui kepatuhan mengkonsumsi obat anti diabetik dan aktifitas fisik. menganalisis hubungan aktifitas fisik, kepatuhan mengkonsumsi obat anti diabetik, dengan kadar gula darah penderita DM tipe 2 rawat jalan di Fasyankes Primer Klaten. Jenis penelitian adalah analitik observasional dengan desain cross sectional. Populasi adalah pasien DM yang berkunjung di Fasyankes Primer Klaten. Sampel 86 pasein, ditarik secara random sampling. Pengumpulan data menggunakan kuesioner dan dokumentasi. Teknik analisa data menggunakan uji Chi Square dan regresi logistik ganda. Aktifitas fisik berkategori tinggi berhubungan dengan kadar gula darah $(\mathrm{p}=0,021)$, kategori rendah dan sedang tidak berhubungan dengan kadar gula darah $(\mathrm{p}=0,061)$. Kepatuhan mengkonsumsi obat anti diabetik berkategori tinggi, berhubungan dengan kadar gula darah $(p=0,002)$, berkategori rendah dan sedang tidak berhubungan dengan kadar gula darah $(p=0,066)$. Secara simultan, kepatuhan mengkonsumsi obat anti diabetik dan aktifitas fisik berhubungan dengan kadar gula darah. Kesimpulan kepatuhan mengkonsumsi obat anti diabetik dan aktifitas fisik berhubungan dengan kadar gula darah $(\mathrm{p}=0.001)$.
\end{abstract}

Kata kunci: Aktifitas fisik, gula darah, kepatuhan

\section{The Relationship Between of Physical Activity and Adherence to Take Oral Hypoglycemic Drug (OHD) with Blood Glucose on Type 2 Diabetes Mellitus Patient in the Primary Fasilitaty Health Centers in Klaten}

\begin{abstract}
Diabetes mellitus (DM) is a metabolic disorder with hyperglycemia characteritic caused by insulin secretion disturbance, Besides death, DM also cause the patient handicap. 30\% DM patient experience of the blindness effect of complicated retinopati and $10 \%$ amputasion of feet, so that management DM was very importance. Reachable DM Management efficacy through the adherence to take the Oral Hypoglycemic Drug (OHD) and physical activity. Objective to determine the relationship between physical activity and adherence to Take Oral Hypoglycemic Drug with blood glucose on Type 2 diabetes mellitus Patient. This study was on observational analytic with cross sectional approach. The population was patients who visit in Primary Fasilitaty Health Centers in Klaten. Members of 86 sampel performed random sampling technique. Data were collected by questionnsire method and documentation. Data analysis techniques using Chi Square and multiple logistic regression. there was relationship between the high level of physical activity with blood glucose levels $(p=0,021)$, but there weren't relationship between the low and moderate level of physical activity with blood glucose $(p=0.061)$. The high level of adherence to take oral hyphoglycemic drug was relationship with blood glucose $(p=0,002)$, but there was not relationship between the low and moderate level of adherence to take oral hyphoglycemic drug with blood glucose $(p=0,066)$. By simultan, the physical activity and adherence to take oral hyphoglycemic drug was relationship with blood glucose. Conclution there is significant relationship between physical activity and adherence to take oral hyphoglycemic drug with blood glucose levels in type 2 diabetes mellitus patients. $(p=0,001)$.
\end{abstract}

Keyword: Adherence, blood glucose, physical activity

Korespondensi:

Cahyono Widodo

Prodi Magister Kedokteran Keluarga Program Pascasarjana Universitas Negeri Sebelas Maret

Jl. Sutami No. 36A. Surakarta Jawa Tengah 57126

Mobile : 08122718501

Email :cahyono_w67@yahoo.com 


\section{Pendahuluan}

Diabetes Mellitus (DM) merupakan sekelompok penyakit metabolik yang ditandai oleh kenaikan kadar glukosa dalam darah atau hiperglikemia karena adanya kelainan sekresi insulin, kerja insulin atau keduanya (Smeltzer dan Bare, 2008). Gangguan tersebut dapat disebabkan oleh sekresi hormon insulin tidak adekuat atau fungsi insulin terganggu (resistensi insulin). Selain kematian, diabetes mellitus juga menyebabkan kecacatan, yang sangat berpengaruh terhadap kualitas hidup dari pasien DM sendiri. Sebanyak 30\% pasien DM mengalami kebutaan akibat komplikasi retinopati dan $10 \%$ menjalani amputasi tungkai kaki (International Diabetic Federation, 2006).

Prevalensi kejadian diabetes melitus (DM) meningkat di Indonesia, prediksi IDF (International Diabetes Federation), penderita DM di Indonesia tahun 2020 berjumlah 178 juta penduduk yang berusia di atas 20 tahun dan dengan asumsi prevalensi DM sebesar 4,6\% akan didapatkan 8,2 juta pasien DM (Soegondo, Soewondo dan Subekti, 2009). Tingginya prevalensi DM tersebut menyebabkan Indonesia berada pada peringkat ke empat jumlah penderita DM terbanyak di dunia setelah Amerika Serikat, India, dan Cina. Menurut prediksi para ahli epidemiologi menyebutkan angka prevalensi yang makin meningkat dimasa yang akan datang, akan menempatkan diatetes mellitus sebagai The Global Epidemy (PERKENI, 2006).

Pengelolaan DM dapat dilakukan melalui diet, latihan (olahraga), Obat-obatan, dan penyuluhan yang berkelanjutan serta membimbing penderita DM sehingga pasien DM menjadi mandiri. Keseimbangan antara diet, latihan, obat-obatan dan penyuluhan sangatlah penting. sebab diet yang sesuai dengan kebutuhan, kepatuhan mengkonsumsi obat-obatan, dan disertai dengan latihan yang teratur akan membantu pengambilan glukosa dalam darah oleh otot-otot yang aktif pada saat berolahraga. Aktivitas fisik merupakan kunci dalam pengelolaan diabetes mellitus terutama sebagai pengontrol gula darah dan memperbaiki faktor resiko kardiovaskuler seperti menurunkan hiperinsulinemia, meningkatkan sensitifitas insulin (Plotnikoff, 2006). Keberhasilan pengelolaan DM dapat dicapai melalui kepatuhan penderita DM dalam menjalani terapi baik farmakologi maupun non farmakologi. Aktivitas fisik adalah gerakan yang dilakukan oleh otot tubuh dan sistem penunjangnya (Wilmore et al., 2004). Menurut Haskell, aktivitas fisik adalah sesuatu yang menggunakan tenaga atau energi untuk melakukan berbagai kegiatan fisik, seperti berjalan, berlari, dan berolahraga (Haskell et al., 2007). WHO (2013) menyatakan bahwa aktivitas fisik adalah setiap gerakan tubuh yang meningkatkan pengeluaran tenaga dan energi (pembakaran kalori).

Aktivitas fisik berbeda dengan olahraga/ latihan jasmani. Aktivitas fisik adalah semua gerakan otot bergaris yang membakar energi tubuh. Sedangkan olahraga ialah gerakan tubuh yang berirama dan teratur untuk memperbaiki dan meningkatkan kebugaran. Olahraga meliputi segala macam pelatihan. Aktivitas fisik mencakup semua olahraga, semua gerakan tubuh, semua pekerjaan, rekreasi, kegiatan sehari-hari, sampai pada kegiatan pada waktu senggang. Aktivitas fisik yang dianjurkan untuk para penderita diabetes melitus tipe 2 adalah aktivitas fisik secara teratur (3-4 kali seminggu) selama kurang lebih 30 menit dan sesuai CRIPE (continuous, rhythmical, interval, progresive, endurance training), serta diusahakan mencapai 75-85\% denyut nadi maksimal (Waspadji, 2011)

Keberhasilan pengelolaan DM dapat dicapai melalui aktifitas fisik, dan diimbangi dengan kepatuhan mengkonsumsi obat anti diabetik sebagai wujud dari intervensi farmakologis. Hasil penelitian Putri menunjukkan bahwa terdapat hubungan antara kepatuhan pengobatan dengan rerata kadar gula darah (Putri, 2013).

Kepatuhan adalah tingkat perilaku yang tertuju terhadap instruksi atau petunjuk yang diberikan dalam bentuk terapi apapun yang ditentukan, baik diet, latihan, pengobatan atau menepati janji pertemuan dengan dokter. Kepatuhan seseorang sangat berhubungan dengan Interaksi kompleks antara dukungan keluarga dan pengalaman; Interaksi perilaku dengan kepercayaan kesehatan seseorang; Kepercayaan yang ada sebelumnya. Kepatuhan merupakan suatu perubahan perilaku dari perilaku yang tidak mentaati perturan ke perilaku yang mentaati peraturan.

Tingkat kepatuhan dapat diukur melalui metode tidak langsung dengan menggunakan kuesioner Morisky Medication Adherence Scale (MMAS)-8 Kuesioner MMAS-8 adalah alat penilaian dari WHO yang sudah divalidasi dan digunakan untuk menilai kepatuhan pengobatan pasien dengan penyakit kronik, seperti diabetes mellitus Berdasarkan uraian tersebut, peneliti ingin melakukan penelitian dengan tujuan untuk mengetahui hubungan aktivitas fisik dan kepatuhan mengkonsumsi obat anti diabetik dengan kadar gula darah pada pasien DM tipe 2 di Fasyankes Primer di Klaten

\section{Metode}

Penelitian ini merupakan penelitian observasi analitik dengan desain studi cross-sectional. 
Dilaksanakan di fasyankes primer Klaten, mulai dari bulan September sampai dengan bulan Oktober 2015. Populasi yang ditetapkan oleh peneliti adalah pasien DM tipe 2 sebanyak 1009 orang yang berobat di 35 fasyankes primer. Karena tingkat pelayanan sama (homogen), digunakan metode sampling melalui pengklasteran menjadi 28 cluster. Dari cluster yang terpilih ditarik sampel sebanyak 86 pasien melalui teknik random sampling. Semua data hasil penelitian dari sampel terpilih dijaga kerahasiaannya. Kriteria inklusi dalam penelitian ini adalah a) Pasien DM tipe 2 yang berobat jalan di Fasyankes primer Klaten dan b) Pasien DM tipe 2 yang menggunakan obat anti diabetes oral. Sedangkan kriteria eksklusinya adalah a). Pasien DM tipe 2 dengan komplikasi seperti kardiovaskular, syaraf, mata dan kulit, dan b). Pasien wanita hamil. Penelitian ini menggunakan MMAS-8 untuk mengukur Tingkat kepatuhan minum Obat Hipoglikemik Oral dan instrument IPAQ untuk mengukur aktifitas fisik. Sedangkan Kadar Glukosa Darah (KGD) dengan melihat rekam medis responden.

\section{Hasil}

Karakteristik Responden, dari tabel 1 Kadar Gula Darah tidak terkontrol (penderita diabetes Mellitus 2) lebih banyak dialami oleh perempuan yaitu sebanyak 32 orang ( $66,7 \%)$, dengan kelompok umur di atas 50 tahun $(45,8 \%)$. Faktor jenis kelamin tidak memiliki hubungan yang signifikan dengan gula darah tidak terkontrol atau kejadian diabetes $(p=0,404)$, tetapi jenis kelamin laki-laki memiliki kemungkinan sebesar 0,688 kali lipat untuk dapat mengendalikan Kadar Gula Darah dibandingkan dengan perempuan.

Tabel 1 Distribusi Sampel Secara Umum

\begin{tabular}{lcccc}
\hline \multicolumn{1}{c}{ Karakteristik } & $\begin{array}{c}\text { Kadar Gula Darah } \\
\text { (Terkontrol) }\end{array}$ & $\begin{array}{c}\text { Kadar Gula Darah } \\
\text { (Tidak Terkontrol) }\end{array}$ & OR (CI 95 \%) & Nilai p \\
\hline Jenis Kelamin & & & & \\
Laki - laki & $16(42,1 \%)$ & $16(33,3 \%)$ & $0,688(0,285-1,658)$ & 0,404 \\
Perempuan & $22(57,9 \%)$ & $32(66,7 \%)$ & ref & \\
Umur & & & & \\
$20-35$ tahun & $14(36,8 \%)$ & $12(25,0 \%)$ & $0.312(0,102-0,953)$ & 0.041 \\
$36-50$ tahun & $16(42,1 \%)$ & $14(29,2 \%)$ & $0,318(0,108-0,938)$ & 0.038 \\
$\geq 50$ tahun & $8(21,1 \%)$ & $22(45,8 \%)$ & ref & \\
Aktifitas Fisik & & & & \\
Tinggi & $10(26,3)$ & $6(12,5 \%)$ & $0,210(0,056-0,796)$ & 0,021 \\
Sedang & $21(55,3)$ & $22(45,8 \%)$ & $0,367(0,129-1,046)$ & 0,061 \\
Rendah & $7(18,4)$ & $20(41,7 \%)$ & ref & \\
Kepatuhan Minum & & & & \\
OHO & & & & \\
Tinggi & $14(36,8 \%)$ & $6(12,5 \%)$ & $0,143(0,041-0,497)$ & 0.002 \\
Sedang & $16(42,1 \%)$ & $18(37,5 \%)$ & $0,375(0,132-1,067)$ & 0.066 \\
Rendah & $8(21,1 \%)$ & $24(50,0 \%)$ & ref & \\
Total & 38 & 48 & & \\
\hline
\end{tabular}

Tabel 2 Chi Square test

\begin{tabular}{lccc}
\hline \multicolumn{1}{c}{ Variabel } & Value & df & Sig \\
\hline Jenis Kelamin & $0,699^{\mathrm{a}}$ & 1 & 0,403 \\
Umur & $5,746^{\mathrm{a}}$ & 2 & 0,0057 \\
Kepatuhan OHO & 10,294 & 2 & 0,006 \\
Aktivitas Fisik & $6,201^{\mathrm{a}}$ & 2 & 0,045 \\
\hline
\end{tabular}


Secara keseluruhan, faktor umur tidak berhubungan dengan pengendalian $\operatorname{KGD}(\mathrm{p}=$ 0,057 ), tetapi kelompok umur $20-35$ tahun dan umur $36-50$ tahun, mempunyai hubungan yang signifikan dengan pengendalian KGD. Masingmasing memiliki nilai p sebesar 0,041 atau lebih kecil dari 0,05 untuk kelompok umur 20-35 tahun dan 0,038 untuk kelompok umur 36-50 tahun. Kelompok umur $20-35$ tahun memiliki kemungkinan sebesar 0,312 kali lipat untuk dapat mengendalikan KGD dibanding kelompok umur di atas 50 tahun, dan kelompok umur 36-50 tahun memiliki kemungkinan sebesar 0,318 kali lipat untuk dapat mengendalikan Kadar Gula Darah dibangding kelompok umur lebih dari 50 tahun.

Berdasarkan tabel 2 dapat diketahui bahwa variabel jenis kelamin $(p=0,403)$ dan variabel Umur $(\mathrm{p}=0,057)$ tidak berhubungan secara signifikan dengan kadar gula darah (nilai $p$ $>$ 0,05). Variabel kepatuhan minum OHO berhubungan dengan kadar gula darah $(p=0,006)$, dan Aktivitas fisik berhubungan dengan kadar gula darah $(\mathrm{p}=0,045)$.

Hubungan Kepatuhan Minum Obat Anti Diabetik dengan Kadar Gula Darah; Berdasarkan tabel 3, Kadar Gula Darah (terkontrol) yang memiliki hubungan secara signifikan adalah tingkat kepatuhan mengkonsumsi obat anti diabetik dalam kategori tinggi, $\mathrm{p}=0,0022$. Tingkat kepatuhan minum obat dalam kategori tinggi memiliki kemungkinan sebesar 0,143 kali lipat dibanding yang berkategori rendah dalam melakukan pengendalian KGD nya. Kesimpulannya tingkat kepatuhan minum obat anti diabetik dalam kategori tinggi memiliki hubungan yang signifikan dengan KGD yaitu $\mathrm{p}$ $=0,002$, akan tetapi tingkat kepatuhan kategori sedang dan rendah tidak memiliki hubungan yang signifikan dengan KGD karena $p=0,066>0,05$

Hubungan antara Aktifitas Fisik dengan Kadar Gula Darah; Dari tabel 4, KGD terkontrol yang paling banyak memiliki tingkat aktifitas fisik dalam kategori sedang yaitu sebanyak 21 orang atau sebesar 55,3\%. Untuk orang dengan aktifitas fisik dalam kategori sedang, memiliki kemungkinan sebesar 0,367 kali lipat dibanding yang berkategori rendah dalam melakukan pengendalian KGDnya. Akan tetapi tingkat aktifitas fisik dalam kategori sedang, tidak memiliki hubungan yang signifikan dengan KGD karena nilai $p=0,061>\alpha$ yaitu 0,05 .

Tingkat Aktifitas fisik tinggi dengan KGD terkontrol sebanyak 10 orang $(26.3 \%)$, tingkat aktifitas fisik dalam kategori tinggi memiliki kemungkinan sebesar 0,210 kali lipat dibanding yang berkategori rendah dalam mengendalikan KGDnya. Tingkat aktifitas fisik kategori tinggi berhubungan secara signifikan dengan KGD, karena nilai $p=0,021$ atau lebih kecil dari $\alpha$ yaitu 0,05. Kesimpulannya, secara umum tingkat aktifitas fisik memiliki hubungan yang signifikan dengan KGD yaitu $\mathrm{p}=0,015$ atau lebih kecil dari $\alpha=0,05$. Aktifitas fisik dengan kategori tinggi memiliki hubungan yang signifikan dengan KGD karena $p=0,021$; akan tetapi aktifitas fisik dalam kategori sedang tidak memiliki hubungan yang signifikan dengan KGD karena $\mathrm{p}=0,06$

\section{Tabel 3 Distribusi Responden menurut Kepatuhan Minum Obat Anti Diabetik dengan Kadar} Gula Darah.

\begin{tabular}{lcccc}
\hline Tingkat & \multicolumn{4}{c}{ Kadar Gula Darah } \\
\cline { 2 - 5 } Kepatuhan & Terkontrol & Tidak Terkontrol & OR (CI 95 \%) & p \\
\hline Tinggi & $14(36.8 \%)$ & $6(12.5 \%)$ & $0,143(0,041-0,497)$ & 0.002 \\
Sedang & $16(42.1 \%)$ & $18(37.5 \%)$ & $0,375(0.132-1,607)$ & 0.066 \\
Rendah & $8(21.1 \%)$ & $24(50 \%)$ & ref & \\
\hline
\end{tabular}

Tabel 4 Distribusi Responden menurut Aktifitas Fisik dengan Kadar Gula Darah.

\begin{tabular}{lcccc}
\hline Aktifitas & \multicolumn{4}{c}{ Kadar Gula Darah } \\
\cline { 2 - 5 } Fisik & Terkontrol & Tidak Terkontrol & OR (CI 95 \%) & p \\
\hline Tinggi & $10(26,3 \%)$ & $6(12,5 \%)$ & $0,210(0,056-0.793)$ & 0.021 \\
Sedang & $21(55,3 \%)$ & $22(45,8 \%)$ & $0,367(0.129-1,046)$ & 0.061 \\
Rendah & $7(218,4 \%)$ & $20(41,7 \%)$ & ref & \\
\hline
\end{tabular}


Tabel 5 Hasil Regresi Logistik

\begin{tabular}{lccc}
\hline Variabel & B & Sig & OR (CI 95\%) \\
\hline Konstant & 4,541 & 0,001 & - \\
Jenis Kelamin & 0,543 & 0,248 & $1,721(0,637-4,647)$ \\
Umur & $-0,656$ & 0,333 & $0,519(0,137-1,961)$ \\
Aktifitas Fisik & $-0,948$ & 0,010 & $0,387(0,188-0,800)$ \\
Kepatuhan minum obat & $-1,325$ & 0,001 & $0,266(0,118-0,601)$ \\
\hline
\end{tabular}

Analisis Regresi Logistik Ganda; Analisis regresi logistik ganda digunakan karena dependen yang dipertanyakan terdiri atas rangkaian angka dalam bentuk kategorikal. Analisis dilakukan dengan bantuan program SPSS 16.0. Berdasarkan tabel 5 dapat diketahui bahwa besaran konstant atau nilai intercept adalah 4,541. Koefisien variabel jenis kelamin sebesar 0,543 dengan OR $=1,721$ dan sig $=0,248$, artinya jenis kelamin laki-laki memiliki kemungkinan sebesar 1,721 kali lipat dibanding yang berjenis kelamin perempuan dalam mengendalikan KGDnya akan tetapi sifat hubungannya tidak signifikan ( $0,248>0,05)$. Koefisien variabel umur sebesar $-0,656$ dengan $\mathrm{OR}=0,519$ dan $\mathrm{sig}=0,333$. Koefisien variabel kepatuhan minum obat anti diabetik sebesar $-1,325$ dengan $\mathrm{OR}=0,266$ dan $\operatorname{sig}=0,001$. Sedang koefisien variabel aktifitas fisik sebesar $-0,948$ dengan $\mathrm{OR}=0,387$ dan signifikansi $=0,010$. Dengan demikian model persamaan regresi logistik ganda: Ln $\mathrm{p} /(1-\mathrm{p})$ $=4,451+0,543 \times 1$ (Jenis kelamin $)-0,656 \times 2$ (Umur) - 1,325 x5 (Kepatuhan minum obat) $1,948 \times 6$ (Aktifitas fisik), atau y $=4,451+0,543$ x1 - 0,656 x2-1,325 x5-1,948 x6.

Kesimpulan yang dapat ditarik adalah bahwa model yang digunakan sebagai alat analisis telah sesuai dengan data empirik yang ada, dan variabel kepatuhan minum obat maupun variabel aktifitas fisik memiliki hubungan yang signifikan dengan variabel kadar gula darah. Besarnya Odds Ratio $<1$, maka variabel independen kepatuhan minum obat dan variabel aktifitas fisik merupakan faktor protektif.

\section{Pembahasan}

Dari penelitian di atas dapat disimpulkan bahwa ada hubungan antara kepatuhan minum obat anti glikemik dan aktifitas fisik dengan Kadar Gula Darah sebagaimana ditunjukkan oleh hasil uji chi square yaitu hubungan antara kepatuhan minum obat anti glikemik dengan Kadar Gula darah $(p=0.006)$. dan hubungan antara aktifitas fisik dengan Kadar Gula Darah $(p=0,045)$.
Disamping itu secara simultan melalui uji regresi logistik ganda menunjukkan nilai $\mathrm{p}=0,001$, artinya ada hubungan yang signifikan.

Dari hasil analisis diketahui bahwa kepatuhan minum obat anti diabetik dalam kategori tinggi, berhubungan secara signifikan dengan Kadar Gula darah $(\mathrm{p}=0.002)$. Hasil penelitian ini juga sejalan dengan penelitian yang dilakukan oleh Sri Anani (2012) dalam penelitiannya yang berjudul: hubungan antara perilaku pengendalian diabetes mellitus di RSUD Anjarwinangun Kabupaten Cirebon. Kesimpulan yang ditarik adalah perilaku pengendalian diabetes mellitus yang baik dapat mengontrol kadar gula darah dalam batas normal. Demikian pula dengan beberapa studi yang menunjukkan bahwa kesulitan dalam mengelola penyakit secara berkala seperti oral hipoglikemik menyebabkan seorang penderita diabetes mellitus dapat menjadi tidak patuh dalam mengontrol gula darahnya. Perilaku tidak patuh akan memperberat penyakit yang dideritanya (Cramer, 2004). Sedang Safitri (2013) dalam penelitiannya menyatakan bahwa 63,9 \% responden tidak mampu mengendalikan dirinya dan sebesar $25 \%$ responden yang berhenti minum obat jika kondisinya membaik atau memburuk. Akan tetapi hasil penelitian ini tidak relevan dengan hasil penelitian Qadrianty, dkk. (2014)., yang melaporkan bahwa sekitar $80 \%$ responden dengan kepatuhan minum $\mathrm{OHO}$ kategori sedang-tinggi, memiliki kadar GDP tidak terkontrol. Kesimpulan yang ditarik, tidak ada hubungan antara tingkat kepatuhan minum $\mathrm{OHO}$ responden dengan kadar glukosa darah puasa responden. Berdasarkan uji Fisher $,==0,655(p>0,05)$. Hasil penelitian ini serupa dengan penelitian Qurratuaeni (2009), bahwa tidak terdapat hubungan antara asupan obat pasien $(\mathrm{p}=0,503)$ dengan pengendalian kadar gula darah. Berdasarkan hasil analisis juga diketahui bahwa kepatuhan minum $\mathrm{OHO}$ dalam kategori sedang dan rendah memiliki nilai $\mathrm{p}=$ $0,066(>0,05)$. Artinya dapat disimpulkan bahwa tidak terdapat hubungan yang signifikan antara kepatuhan minum $\mathrm{OHO}$, dalam kategori sedang dan rendah dengan kadar gula darah (GDP).

Hasil penelitian ini relevan dengan hasil penelitian Qadrianty, dkk. (2014)., yang 
menyimpulkan bahwa tidak ada hubungan antara tingkat kepatuhan minum $\mathrm{OHO}$ dengan kadar GDP responden $(\mathrm{p}=0,561)$. Demikian pula dengan hasil penelitian yang dilakukan Qurratuaeni (2009) yang menyatakan bahwa tidak terdapat hubungan yang signifikan antara asupan obat pasien $(\mathrm{p}=0,053)$ dengan pengendalian gula darah. Walaupun tidak ada kesamaan hasil antara kepatuhan minum $\mathrm{OHO}$ kategori tinggi( $\mathrm{p}=0,002)$ dengan Kategori sedang dan rendah $(\mathrm{p}=0,066)$, namun secara keseluruhan dapat disimpulkan bahwa kepatuhan minum $\mathrm{OHO}$ memiliki hubungan yang signifikan dengan kadar GDP, $\mathrm{p}=0,001(<0,05)$.

Dari hasil analisis diketahui bahwa aktifitas fisik dalam kategori tinggi, berhubungan secara signifikan dengan Kadar Gula Darah $(\mathrm{p}=0.021)$. Hasil penelitian ini relevan dengan penelitian terdahulu, seperti penelitian Ramadhanisa (2013) yang menyatakan bahwa ada hubungan antara aktifitas fisik dengan kadar HbAlc pada pasien DM tipe 2. Penelitian Meta-analysis yang dilakukan Boule \& Sigal (2003) juga menyimpulkan bahwa peningkatan intensitas olahraga dapat meningkatkan kerja jantung dan menurunkan kadar gula dalam darah (HbA1C) pada pasien DM tipe 2. Penelitian Shenoy et al. (2010) tentang efektivitas program olahraga, menunjukkan hasil bahwa program aerobic dan jalan dapat menurunkan glukosa darah sebesar $37 \%$. Manfaat olahraga bagi penderita DM adalah menurunkan kadar glukosa darah, meningkatkan sensitivitas insulin serta menurunkan tekanan darah (Praet \& Loan, 2009).

Penelitian Nirwanto (2015) tentang "Pengaruh Senam Diabetes Terhadap Penurunan Kadar Gula Darah Sewaktu Pada Pasien dengan DM tipe II di Wilayah Kerja Puskesmas Global Kec. Limboto Kab. Gorontalo", dengan uji statistik t berpasangan, menunjukkan hasil bahwa senam Diabetes berpengaruh terhadap Penurunan Kadar Gula Darah Sewaktu (p value 0,000 atau $<0,05$ ). Penelitian eksperimen yang dilakukan oleh Sigal et al, (2007) menyimpulkan bahwa olahraga aerobic dan latihan resisten meningkatkan HbA1C tetapi kontrol gula darah menjadi lebih bagus. Aktifitas fisik dapat meningkatkan sensitivitas insulin, menurunkan level $\mathrm{HbA} 1 \mathrm{c}$ dan memperbaiki profil lipid. Permeabilitas membran terhadap glukosa meningkat saat otot berkontraksi karena kontraksi otot memiliki sifat seperti insulin. Maka dari itu, pada saat beraktivitas fisik seperti berolahraga, resistensi insulin berkurang. Aktivitas fisik dalam kategori sedang dan rendah, berdasarkan hasil analisis menyatakan bahwa tidak ada hubungan yang signifikan antara aktivitas fisik dengan kadar GDP $(\mathrm{p}=0,061)$. Hasil penelitian ini relevan dengan hasil penelitian Suci Qadrianty, dkk. (2014) yang menyatakan bahwa tidak ada hubungan antara tingkat aktivitas fisik dengan kadar glukosa darah puasa pada penderita diabetes mellitus tipe 2 , berdasarkan uji Fisher dengan $\mathrm{p}=0,655(>0,05)$.

Berdasarkan hasil penelitian, memang ada perbedaan, satu sisi aktivitas fisik berkategori tinggi memiliki hubungan yang signifikan dengan kadar gula darah, sementara disisi lain aktivitas fisik dengan kategori sedang dan rendah tidak memiliki hubungan dengan kadar glukosa darah puasa. Walaupun demikian secara keseluruhan, aktivitas fisik memiliki hubungan dengan kadar gula darah puasa, $\mathrm{p}=0,041(<0,05)$

Berdasarkan analisis dengan uji regresi logistik ganda diperoleh persamaan $\mathrm{y}=4,451+$ $0,543 \times 1-0,656 \times 2-1,325 \times 5-1,948 \times 6$

Kesimpulan yang dapat ditarik adalah bahwa model yang digunakan sebagai alat analisis telah sesuai dengan data empirik yang ada, dan variabel kepatuhan mengkonsumsi obat maupun variabel aktifitas fisik memiliki hubungan yang signifikan dengan variabel kadar gula darah. Besarnya Odds Ratio $<1$, mengandung arti bahwa variabel independen kepatuhan mengkonsumsi obat dan variabel aktifitas fisik merupakan faktor protektif atau memiliki hubungan yang bersifat negatif.

Berdasarkan pada hasil analisis di atas, maka dapat dinyatakan bahwa terdapat hubungan yang signifikan antara kepatuhan mengkonsumsi obat anti diabetik dan aktivitas fisik dengan kadar gula darah.

Keterbatasan Penelitian; Pelaksanaan penelitian di lapangan, peneliti memiliki keterbatasan-keterbatasan yang dapat berpengaruh terhadap hasil penelitian ini. Keterbatasan tersebut antara lain bahwa peneliti tidak dapat secara langsung melakukan kontrol terhadap aktivitas responden setiap hari.Terutama karena responden melakukan aktivitas yang saling berbeda dan dalam waktu yang tidak sama. Disamping itu tempat tinggal responden yang saling berjauhan merupakan kesulitan dalam melaksanakan monitoring baik dalam kepatuhan mengkonsumsi obat maupun aktifitas nya

Kesimpulan berdasarkan deskripsi dari dasar teori variabel-variabel yang diteliti dan hasil temuan penelitian, dapat ditarik kesimpulan bahwa terdapat hubungan yang signifikan antara kepatuhan mengkonsumsi obat anti diabetik dan aktifitas fisik baik secara sendiri-sendiri maupun secara bersama-sama (simultan) dengan kadar gula darah.

Berdasarkan kesimpulan di atas, maka disarankan; Disarankan terutama kepada penderita DM tipe 2, khususnya responden yang memiliki tikat aktivitas fisik dalam kategori sedang dan rendah agar meningkatkan aktivitas 
fisiknya dalam kehidupan sehari-hari. Atau paling tidak aktivitas fisik yang dilakukannya minimal 3 kali dalam seminggu dengan durasi waktu sekitar 30 menit per harinya. Disamping itu harus ada kesadaran untuk patuh mengkonsumsi obat anti diabetik sesuai anjuran dokter atau tenaga kesehatan yang melayaninya, agar dapat terhindar dari timbulnya komplikasi;Kepada praktisi kesehatan dan peneliti bidang kesehatan untuk senantiasa menggali faktor-faktor yang mempengaruhi perkembangan dan perjalanan penyakit DM khususnya agar dapat melakukan tindakan pengobatan yang lebih komprehensif.

\section{Daftar Pustaka}

1. Smeltzer, S \& Bare. Brunner \& Suddarth's Textbook of medical surgical nursing. Philadelpia: Lippincott; 2008

2. International Diabetes Federation, Diabetes Atlas 3rd Editionl. Belgium: World Diabetes Foundation; 2006.

3. Soegondo, S., Soewondo, P, \& Subekti, I. Penatalaksanaan diabetes melitus terpadu. Jakarta: Fakultas Kedokteran Universitas Indonesia; 2009

4. PERKENI (Perkumpulan Endokrinologi Indonesia). Perkemahan Diabetes Nasional,2006 (diunduh 15 Oktober 2015). Tersedia dari: http://endokrinologi. Free servers.com/kons dm 98

5. Plotnikoff, R. C. Physical Activity in the Management of Diabetes: Population-based Perspectives and Strategies. Canadian Journal of Diabetes. 2006. 30: 52-62

6. Wilmore, J. H. and Costill, D. L. Physiology of Sport and Exercise, Human Kinetics Publishers, United States of America; 2004

7. Haskell, W. L., I. Lee, R. R. Pate, K. E. Powell, S. N. Blair, B. A. Franklin, C. A. Macera, G. W. Heath, P. D. Thompson and A. Bauman. "Physical activity and public health: updated recommendation for adults from the American College of Sports Medicine and the American Heart Association." Medicine and science in sports and exercise. 2007; 39(8): 1423.

8. WHO Diabetes. 2013 (diunduh 16 Oktober 2015). Tersedia dari: http://www.who.int

9. Waspadji, S. Pedoman Diet Diabetes Melitus. Jakarta:Balai Penerbit FK UI; 2011

10. Putri NHK, Isfandiari MA. Hubungan Empat Pilar Pengendalian DM Tipe 2 dengan Rerata Kadar Gula Darah. Jurnal Berkala Epidemiologi. 2013;1(2):234-43.

11. Anani S. .Hubungan Antara Perilaku
Pengendalian Diabetes Dan Kadar Glokusa Darah Pasien Rawat Jalan Diabetes Mellitus, Jurnal Kesehatan Masyarakat, 2012; Volume 1 Nomor 2.

12. Cramer J. A. A Systematic Review of Adherence With Nedication for Diabetes. Pro Quest Agriculture Journals, 2004; Pg 2284.

13. Safitri IN. Kepatuhan Penderita Diabetes Mellitus Tipe II Ditinjau Dari Locus of Control. Jurnal Ilmiah Psikologi Terapan Fakultas Psikologi Universitas Muhammadiyah Malang, 2013;1(2)

14. Qadrianty, S., Hadju,V., Jafar, N. 2014. Hubungan Tingkat Aktivitas Fisik danTingkat Kepatuhan Minum OHO (Obat Hipoglikemik Oral) dengan KadarGlukosa Darah pada Penderita Diabetes Melitus tipe 2 Rawat Jalan diPuskesmas Kota Makassar.

15. Qurratuaeni. Faktor-Faktor yang Berhubungan dengan Terkendalinya Kadar Gula Darah pada Pasien Diabetes Melitus di Rumah Sakit Umum Pusat (RSUP) Fatmawati Jakarta Tahun 2009 [Skripsi]. Jakarta: Universitas Islam Negeri Syarif Hidayatullah Jakarta; 2009.

16. Ramadhanisa A, Larasati $T$, Mayasari D. Hubungan Aktivitas Fisik Dengan Kadar HbA1c Pasien Diabetes Melitus Tipe 2 Di Laboratorium Patologi Klinik RSUD Dr. H. Abdul Moeloek Bandar Lampung. Medical Journal of Lampung University. 2013; 2(4).

17. Boule \& Sigal, R. J. (2003). Meta-analysis of the effect of structured exercise training on cardiorespiratory fitness in Type 2 diabetes Mellitus. Diabetologia, 46 (8), 1071-81.

18. Shenoy, S., Glugany, R. Shandhy, S. Effectiveness of Aerobic Walking programme Using Heart-Rate Monitor and Pedometer on the Parameters of Diabetes Control in Asian Indians with Type 2 diabetes. 2010; (4), 41-5

19. Praet, S. F. E., Loan, L. J. C. V. Exercise Therapy in Type 2 Diabetes. Acta Diabetol Journal, 2009; 46: 263-278.

20. Nirwanto K. Rahim. 2015. Pengaruh Senam Diabetes Terhadap Penurunan Kadar Gula Darah Sewaktu Pada Pasien dengan DM tipe II di Wilayah Kerja Puskesmas Global Kec. Limboto Kab. Gorontalo. Skripsi, Jurusan Program Studi Ilmu Keperawatan, Fakultas Ilmu-Ilmu Kesehatan dan Keolahragaan, Universitas Negeri Gorontalo.

21. Sigal, R. J., Kenny, G. P., Boule, N. G. Wells G. A. Prud home, D., Fortier, P. Jennings, A. \& Jaffey, J. Effects of aerobic training, resistance training, or both on glycemic control in type 2 diabetes. Annals of Internal Medicine,2007; 147: 357-369. 